\title{
BMJ Open Early prediction of typical outcome and mild developmental delay for prioritisation of service delivery for very preterm and very low birthweight infants: a study protocol
}

\author{
Rebecca Caesar, ${ }^{1,2}$ Roslyn N Boyd, ${ }^{1}$ Paul Colditz, ${ }^{3,4}$ Giovani Cioni, ${ }^{5}$ \\ Robert S Ware, ${ }^{1,6}$ Kaye Salthouse, ${ }^{2}$ Julie Doherty, ${ }^{2}$ Maxine Jackson, ${ }^{2}$ \\ Leanne Matthews, ${ }^{2}$ Tom Hurley, ${ }^{7}$ Anthony Morosini, ${ }^{7}$ Clare Thomas, ${ }^{7}$ \\ Laxmi Camadoo, ${ }^{7}$ Erica Baer, ${ }^{7}$ The PREMTiME Study Group
}

To cite: Caesar R, Boyd RN, Colditz P, et al. Early prediction of typical outcome and mild developmental delay for prioritisation of service delivery for very preterm and very low birthweight infants: a study protocol. BMJ Open 2016:6:e010726

doi:10.1136/bmjopen-2015010726

- Prepublication history and additional material is available. To view please visit the journal (http://dx.doi.org/ 10.1136/bmjopen-2015010726).

Received 21 January 2016 Revised 8 April 2016 Accepted 22 April 2016

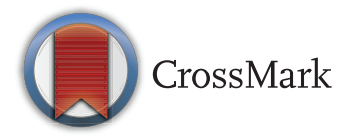

For numbered affiliations see end of article.

Correspondence to

Rebecca Caesar;

rebecca.caesar@health.qld. gov.au

\section{ABSTRACT}

Introduction: Over $80 \%$ of very preterm ( $<32$ weeks) and very low birthweight $(<1500 \mathrm{~g})$ infants will have either typical development (TD) or mild developmental delay (MDD) in multiple domains. As differentiation between TD and MDD can be difficult, infants with MDD often miss opportunities for intervention. For many clinicians, the ongoing challenge is early detection of MDD without over servicing the population. This study aims to: (1) identify early clinical biomarkers for use in this population to predict and differentiate between TD and MDD at 24 months corrected age. (2) Determine the extent to which family and caregiver factors will contribute to neurodevelopmental and behavioural outcomes.

Methods and analysis: Participants will be a prospective cohort of 90 infants ( $<32$ weeks and/or $<1500 \mathrm{~g}$ ). Between 34 weeks gestational age and 16 weeks post-term, infants will have a series of 5 neurological, neuromotor, neurobehavioural and perceptual assessments including General Movement Assessment at preterm, writhing and fidgety age. Primary caregivers will complete questionnaires to identify social risk, maternal depression and family strain. Extensive perinatal data will be collected from the medical record. At 24 months, corrected age (c.a) infants will be assessed using standardised tools including the Bayley Scales of Infant and Toddler Development-Third Edition (Bayley III). Longitudinal trajectories of early assessment findings will be examined to determine any predictive relationship with motor and cognitive outcomes at 24 months c.a. Published data of a cohort of Australian children assessed with the Bayley III at 24 months c.a will provide a reference group of term-born controls.

Ethics: Ethical approval has been obtained from the Queensland Children's Health Services Human Research Ethics Committee (HREC/13/QRCH/66), the University of Queensland (2013001019) and the Sunshine Coast Hospital and Health Service,
SC-Research Governance (SSA/13/QNB/66).

Publication of all study outcomes will be in peerreviewed journals.

Trial registration number: ACTRN12614000480684 Pre-results.

\section{INTRODUCTION}

The absolute number of children born very preterm and very low birth weight (VLBW) is increasing in developed countries as neonatal intensive care continues to improve. ${ }^{12}$ As survival rates increase, the focus moves to consideration of quality of life. ${ }^{1-8}$ The incidence of severe outcomes in the very preterm/VLBW population is beginning to decline but the overall risk of developmental delay across multiple domains remains steady at $47 \% .^{2} 59{ }^{10}$ With rates of typical outcome at $\sim 52 \%$, clinical practitioners are now challenged by the need to differentiate between infants with mild delay and TD. ${ }^{125} 11$

Given the current pressure on public health resources, population intervention is no longer practical nor cost-efficient. Robust early prediction and differentiation is warranted to prevent overservicing of very preterm/VLBW infants who are typically developing and facilitate targeted interventions for infants in the population with higher risk for developmental delay.

In Australia, very preterm children with mild deficits are less likely to receive services than children with more severe outcomes. ${ }^{12}$ Lack of service engagement is even more evident for very preterm children living in situations of higher social or environmental risk. $^{12}$ This is cause for concern as early delays do not dissipate, rather they become 
more apparent with age alongside increasing functional demands in educational and social contexts. $\begin{array}{llll}4 & & 73-16\end{array}$ Late referral often means that infants completely miss out on vital input during critical periods of development when enriched experiences provided by parents and therapists may optimise neuroplasticity. ${ }^{17} 18$

\section{Mild impairment in VLBW and very preterm infants}

Children born very preterm have an increased risk of mild motor delay (MMD) not associated with cerebral palsy (CP). ${ }^{19}$ Prevalence of MMD in children born preterm is three to four times greater than in term-born infants. ${ }^{8} 19$ At 8-12 months corrected age (c.a) nearly half of very preterm infants $(47 \%)$ have mildly delayed scores on the Gross Motor Subscale of the Bayley Scales of Infant and Toddler Development-Third Edition (Bayley III).$^{20}$ At 2.5 years c.a, $29 \%$ of children score 1SD below the control mean on the gross motor and $34 \%$ on the fine motor scale of the Bayley III. ${ }^{21}$ Studies at school age show similar outcomes with one study reporting $32 \%$ and another $50 \%$ of very preterm-born children scoring $\leq 15$ th centile on the Movement Assessment Battery for Children (MABC) at 5 years c.a. ${ }^{7}$

Consistent findings of mild delay in the preterm population from birth to 5 years suggest that motor delays do not improve with time. Instead, early delays progress to motor impairments at school entry that then persist into adolescence. ${ }^{42}$ Developmental coordination disorder is highly prevalent in the VLBW/very preterm population with children six times more likely to score at or below the 5th centile on the MABC, and eight times more likely to score below the 15 th centile. ${ }^{14}$ A meta-analysis of 41 articles encompassing 9653 very preterm/VLBW children from infancy to 15 years found that on average, these children are $-0.57 \mathrm{SD}$ to $-0.88 \mathrm{SD}$ behind their term-born peers or typically developing children in motor development. ${ }^{4}$

Mild motor impairment is rarely experienced in isolation. Children who are born very preterm or VLBW are more likely than term-born infants to perform below average in two or more developmental domains. ${ }^{5} 672021$ Comorbidities that frequently accompany MMD include mild deficits and delay in the cognitive, communication, behavioural, personal-social and perceptual domains including sensory processing differences. ${ }^{1}$ 5-7 9-11 20-24 In very preterm infants where motor delay is identified at 5 years of age, there is a substantially higher rate of impairment in other domains compared with very preterm infants who do not have motor impairment. ${ }^{7}$ Deficits associated with MMD at this age include lower IQ, decreased processing speed, poor visuomotor coordination and increased incidence of complex minor neurological dysfunction. ${ }^{7}$

\section{Biological rationale for multidomain neurodevelopmental deficits}

Preterm birth is timed against a background of significant maturational processes. Between 24 and 40 weeks gestation, multiple developmental events are taking place that include the preoligodendrocytes, microglia, axons, subplate neurons, germinal epithelium of the ganglionic eminence, thalamus, cortex and cerebellum. ${ }^{25}$ Add to this the fragility of a nervous system not prepared for the impact of the extrauterine environment and the result is an immature and actively developing brain vulnerable to insults such as hypoxia, inflammation, ischaemia, excitotoxicity and free radical attack. $^{25-28}$

The high vascularity of the germinal matrix makes it prone to congestion and its fragile capillary system is vulnerable to damage from hypoxia, fluctuations in blood flow velocity and venous congestion. The resulting haemorrhage may leak into the adjacent ventricles or even further into the surrounding white matter. In severe cases, there may be persisting hydrocephalus. ${ }^{28}$

In periventricular leucomalacia, hypoxia causes activation of microglia leading to secretion of toxic oxygen and nitrogen radicals and the release of glutamate. Inflammation secondary to maternal, placental or fetal infection sets in motion the same reaction, releasing the same toxins produced with hypoxia. ${ }^{25} 28$ The principle target of these free radicals and glutamate are the premyelinating oligodendrocytes. Cell loss at this crucial stage results in a deficit of mature oligodendrocytes and impairment of myelination. ${ }^{2527} 28$ There may be accompanying axonal injury resulting in loss and disarray of axons and damage to subplate neurons that will impair connections between the thalamus and cortex. ${ }^{25} 26$

The outcome of this widespread and multifaceted primary and secondary brain injury is impaired white matter development and a decrease in total brain volumes persisting through childhood and into adolescence. ${ }^{18} 252629{ }^{30}$ On average, brain volume in very preterm/VLBW infants is $0.58 \mathrm{SD}$ lower than in term children, with white matter volume reductions of $0.53 \mathrm{SD}$ and grey matter volume reductions of $0.62 \mathrm{SD}$. Reductions are seen in cerebellar volumes, hippocampal volumes and the size of the corpus callosum as well as reduced volumes of the thalamus and basal ganglia. ${ }^{26}$

It is becoming evident that motor, cognitive and perceptual deficits may be more inter-related than previously appreciated. ${ }^{26} 31$ The thalamus and cerebellum, particularly vulnerable to preterm insult, appear to be vital nodes in brain networks playing important roles in cognitive, motor and perceptual tasks. ${ }^{31} 32$ Early impacts to the cerebellum may result in impairment of motor control as well as cognitive ability to learn or organise tasks that are new, difficult, unpredictable, require concentration or need quick responses. ${ }^{31}$

Damage to the thalamus will potentially impact attention, awareness, visually guided actions and perceptual matching of visual space across eye movement. ${ }^{32} 33$ It may also compromise memory and cognition including the cognitive aspects of motor control. ${ }^{34}{ }^{35}$ White matter damage to the posterior thalamic radiations, the corpus callosum, basal ganglia and superior longitudinal 
fasciculus is strongly correlated with atypical unimodal and multisensory integration manifest in sensory processing disorders. ${ }^{36}$ The thalamus also acts with the basal ganglia as a central monitor for language-specific cortical activities and injury may impact on perceptual and productive language execution. ${ }^{37}$

In summary, the interactions occurring between neurological development and biological disturbance in the very preterm/VLBW infant brain are complicated and variable. There are many potential mechanisms for negative impacts on neural structures and connections that are crucial for organisation and coordination of multiple tasks and functions. Subsequently, it is hypothesised that prediction of typical and mildly delayed motor and cognitive outcomes at 24 months c.a will require a combination of fit for purpose clinical tools used across the early developmental trajectory to assess the neurological, neuromotor, neurobehavioral and perceptual functions.

\section{Social risk and environmental impact}

The International Classification of Functioning, Disability and Health clearly indicates that contextual factors have an important influence on activity level and participation. ${ }^{38}$ The very preterm/VLBW infant's developmental outcome is dependent on many variables, including social and environmental influences. ${ }^{1} 11161939$ The impact of gestational age (g.a), perinatal factors and biological insult is mitigated by level of maternal/parental education. ${ }^{22} 40$ Lower socioeconomic status (SES) is also associated with a poorer developmental outcome. ${ }^{12} 163940$ Children with lower SES have significantly lower composite scores on the cognitive, language and motor indices of the Bayley III than children with higher SES. ${ }^{16}$

Premature birth is a stressful event with negative psychological and emotional effects on the family. ${ }^{41}$ This effect is greatest in the first month of life and remains a substantial burden. ${ }^{142}$ At 7 years of age, parents of very preterm children report higher levels of total parenting stress, total parent-related stress and total child-related stress as well as poorer family functioning when compared with families of term-born infants. ${ }^{42}$ As higher rates of stress are associated with lower SES and lower parental education, stress can compound pre-existing environmental and social risk factors. ${ }^{1}$ An important aim of this study is to investigate the extent to which family and caregiver factors will contribute to developmental outcome.

\section{The need for early biomarkers}

By definition, a biomarker, or 'biological marker', is an objective indicator of medical state observed from outside the patient which can be measured accurately and reproducibly. ${ }^{43}$ Biomarkers are used to monitor and predict health states in individuals or across populations, so that appropriate therapeutic intervention can be planned. They can be used separately or in combination to provide a detailed picture of how healthy a person is and whether or not a diagnosis needs to be made. ${ }^{44}$ Biomarkers are used to predict both the healthy and the disease state. ${ }^{43}$ They should be fit for purpose, safe and easy to measure, cost-efficient, modifiable with treatment, and consistent across gender and ethnic groups. $^{44} 45$

The risk of developmental delay in the preterm population increases exponentially as g.a decreases. ${ }^{6} 11$ There is no particular threshold below which risk starts to increase and no g.a that is wholly exempt. ${ }^{16}$ As the causative pathway for developmental delay is multifaceted and there are increasing numbers of infants to consider, clinicians need early biomarkers they can rely on to accurately predict outcomes in order to efficiently and effectively prioritise early intervention services. ${ }^{11}$

There is no single standardised neurodevelopmental assessment tool, or combination of tools, currently advocated or recognised as the 'gold standard' for use with infants in the early months of life to predict typical outcome and mild delay at 24 months c.a. ${ }^{46}$ Instead there are numerous assessments that vary in their physiological basis, pre-requisite training and expertise, time allotted to perform and score, and clinical utility and validity. ${ }^{45} 47^{48} \mathrm{Few}$ of these clinical tools are well suited for use with fragile or sick VLBW/very preterm neonates or in clinical rather than research settings. ${ }^{48}$

In this study, our plan is to explore the potential of five clinical tests, used in combination across the early developmental trajectory, to act as biomarkers for typical and mild outcome in the motor and cognitive domains for very preterm and VLBW infants at 24 months c.a. Ideally, tools that are predictive, valid, safe and easy to administer are a good fit for developmental follow-up in neonatal intensive care, special care, outpatient and community follow-up programmes. Tools that can be used during routine clinical contact offer an easily administered, resource-efficient means of early detection and provide important opportunities for earlier referral to intervention services. ${ }^{50}$

The General Movements (GMs) Assessment of spontaneous movement is the most predictive clinical test of neuromotor function available for use between birth and 20 weeks post-term. ${ }^{45} 48$ The assessment is purely observational and easily administered in clinical settings. Longitudinal assessment of GMs from 34 until 16 weeks post-term will be combined with four other assessment measures: a preterm neurological/neurobehavioural assessment, a neurobehavioural assessment at 2 weeks c.a, and then motor and perceptual function assessment at 16 weeks post-term.

The Premie-Neuro Examination (P-NE) neurological/ neurobehavioural assessment is selected for inclusion at 34 weeks based on excellent clinical utility for use with very preterm infants. It is the only preterm neurological/neurobehavioral assessment with standardised norms from 23 to 37 weeks g.a. Early research suggests evidence of ability to discriminate between high-risk and low-risk infants. ${ }^{49} 51$ 
The Neonatal Intensive Care Unit Network Neurobehavioral Scale (NNNS) will be included at 2 weeks post-term. The NNNS is a neurobehavioural assessment specifically developed for use with 'at-risk' and preterm infants. ${ }^{52}$ When used at term equivalent age it has demonstrated ability to predict motor, cognitive, behavioural and school readiness outcomes between 18 months and 4.5 years. ${ }^{53-55}$

The Alberta Infant Motor Scale (AIMS) is included as the motor assessment with the best combination of clinical utility and predictive validity for outcomes in the second year of life at 16 weeks post-term. ${ }^{45}$ The Infant Sensory Profile 2 (Infant SP2) is a short parent questionnaire and recent revision of the Infant Toddler Sensory Profile (ITSP).$^{56}{ }^{57}$ It is included as the best sensory processing measure available for use from birth. ${ }^{58}$

\section{Broad aim}

The primary aim of this study is to identify clinical biomarkers that can be used between preterm birth and 16 weeks post-term to accurately predict typical development and mild developmental delay in the very preterm and VLBW population at 24 months c.a. Clinicians need reliable biomarkers to make earlier accurate prediction of outcomes to improve prioritisation and promote timely service delivery. A logical strategy is to predict normal outcome and then direct resources towards the smaller pool of 'at-risk' infants. The next step is to predict mild delay as distinct from typical and severe outcomes. As mild delay is the result of complex, intertwined, biological and environmental variables, a combination of biomarkers used across the developmental trajectory is most likely to correlate with later outcomes.

The secondary aim of this study is to determine the extent to which family and caregiver factors including social risk, maternal mental health, and education and family strain will contribute to neurodevelopmental and behavioural outcomes at 24 months c.a.

\section{Primary hypothesis}

Key clinical biomarkers used to assess the developmental trajectory of neurological, neurobehavioural, neuromotor and perceptual function between 34 weeks g.a and 16 weeks post-term will allow accurate prediction of typical outcome and mild developmental delay in the motor and cognitive domains at 24 months c.a.

\section{OVERVIEW OF AIMS}

\section{Aim 1}

To assess the ability of five clinical assessments, GMs, P-NE, NNNS, AIMS and the Infant SP2, administered between 34 weeks g.a and 16 weeks post-term, to predict typical outcomes and mild motor and cognitive delay at 24 months c.a.

Typical outcome is defined as motor and cognitive composite scores no lower than 1SD below the mean on the Bayley III. Mild developmental delay is defined as scores between 1SD and 2SD below the mean, moderate delay by scores between 2SD and 3SD below the mean and severe delay as scores more than 3SD below the mean. ${ }^{5}$

Typical outcome on the Neuro-Sensory and Motor Developmental Assessment (NSMDA) is defined as a motor classification score of 1 or $2{ }^{59} \mathrm{~A}$ score of 1 is defined as within normal limits, a score of 2 as minimal deviation not impacting function. Developmental delay on the NSMDA is defined as a motor classification score $>2$. A score of 3 indicates a mild dysfunction requiring treatment, 4 indicates moderate disability, 5 severe disability and a score of 6 indicates profound impairment. ${ }^{59}$

\section{Hypotheses}

H1a. Higher raw scores on the P-NE ( $>95)$ combined with a 'low-risk' trajectory of GMs, typical profile on the NNNS subscales (10th to 90th centiles) and a normal classification on the AIMS (>10th centile) will predict typical performance (scores above -1SD) on the motor and cognitive subscales of the Bayley III at 24 months c.a and a functional grade of 1or 2 on the NSMDA. ${ }^{46} 51$

$H 1 b$. Lower scores on the P-NE $(<95)$, combined with a 'moderate-risk' or 'high-risk' trajectory of GMs, atypical profile on the NNNS subscales (centile $<10$ or $>90$ ) and a suspicious/abnormal classification on the AIMS $(<10$ th centile) will predict scores $-1 \mathrm{SD}$ or more below the mean on the motor and cognitive subscales of the Bayley III at 24 months c.a and a functional grade $>2$ on the NSMDA.

H1c. Children identified with mild delays (between $-1 \mathrm{SD}$ and $-2 \mathrm{SD}$ below the mean) on the cognitive and motor subscales of the Bayley III subscale will be more likely to have lower scores ( $-1 \mathrm{SD}$ or more below the mean) on the language, adaptive behaviour and social emotional subscales of the Bayley III.

H1d. A typical sensory profile on the Infant SP2 at 16 weeks post-term will be associated with typical motor and cognitive outcomes outcome on the Bayley III at 24 months c.a.

\section{Aim 2}

To examine any associations between the PN-E neurological examination and GMs at preterm and between the PN-E at preterm and longitudinal classification of GM trajectories at 16 weeks post-term. To further determine any predictive association between the PN-E at preterm, the NNNS at 2 weeks post-term and the AIMS and Infant SP2 at 16 weeks post-term.

\section{Hypotheses}

H2a. Higher raw scores on the PN-E at 34-35 weeks g.a $(>95)$ will correlate with normal GMs classification at 34-35 weeks g.a. Lower raw scores on the PN-E at 3435 weeks g.a will correlate with poor repertoire and 
cramped synchronised classification on the GMs at 3435 weeks g.a.

H2b. Raw scores on the PN-E at 34-35 weeks g.a will predict subscale scores on the NNNS (typical or atypical) at 2 weeks post-term.

$H 2 c$. Raw scores on the PN-E at 34 weeks will predict classification of risk on GM trajectories (low, moderate, high), classification on the AIMS (normal, suspicious/ abnormal) and typical or atypical sensory processing on the Infant SP2 at 16 weeks post-term.

\section{Aim 3}

To determine any predictive association between the NNNS at 2 weeks post-term and GM classification at 16 weeks post-term. To further determine any association between the NNNS at 2 weeks post-term and the AIMS and Infant SP2 at 16 weeks post-term.

\section{Hypothesis}

H3a. Subscale scores on the NNNS at 2 weeks post-term (typical or atypical) will predict classification of risk on GM trajectories (low, moderate, high), classification on the AIMS (normal, suspicious/abnormal) and typical or atypical sensory processing on the Infant SP2 at 16 weeks post-term.

\section{Aim 4}

To determine any predictive association between the NNNS at 2 weeks post-term and behavioural outcome at 24 months c.a (Bayley III, Infant-Toddler Social-Emotional Assessment (ITSEA)). To further determine any association between the NNNS at 2 weeks post-term and sensory profile at 24 months c.a.

\section{Hypothesis}

H4a. Subscale scores on the NNNS (typical or atypical) at 2 weeks post-term will predict behavioural and social emotional competencies on the ITSEA and typical or atypical sensory profile on the Infant SP2 at 24 months c.a.

\section{Aim 5}

To examine any association between the Bayley III motor subscale and the motor classification score on the NSMDA at 24 months c.a.

\section{Hypothesis}

H5a. Bayley III motor composite scores will correlate with NSMDA motor classification scores at 24 months c.a.

\section{Aim 6}

To determine the extent to which environmental and social factors including social risk, level of education, incidence of postnatal depression and family strain will be associated with neurodevelopmental and behavioural outcomes at 16 weeks post-term and 24 months c.a.

\section{Hypotheses}

H6a. Early environmental and social factors identified by a Social Risk Index (SRI), the Impact on Family Scale (IOF-G) and the Edinburgh Post Natal Depression Scale (EPDS), will have a predictive association with neurodevelopmental outcome at 16 weeks post-term (AIMS, GMs, Infant SP2) and at 24 months c.a (Bayley III, NSMDA) as well as behavioural outcomes (Bayley III, ITSEA) at 24 months c.a.

H6b. Higher social risk scores, lower maternal level of education and incidence of maternal depression are likely to be confounding variables for predicting cognitive outcome on the Bayley III at 24 months c.a.

\section{Aim 7}

To evaluate the ability of perinatal variables, in particular brain injury on cranial ultrasound (CUS), intrauterine growth restriction (IUGR), bronchopulmonary dysplasia (BPD), necrotising enterocolitis (NEC), severe retinopathy of prematurity (ROP), sex, g.a, late-onset sepsis and breastfeeding status at discharge, to predict mild motor and mild cognitive delay at 24 months c.a (Bayley III, NSMDA). To further evaluate any predictive association between perinatal variables and behavioural outcomes and sensory profile at 24 months c.a (Bayley III, Toddler Sensory Profile 2 (Toddler SP2), ITSEA).

\section{Hypothesis}

H7a. Perinatal factors including brain injury on CUS, BPD, NEC, severe ROP, late-onset sepsis, g.a, sex and breastfeeding status at discharge will predict neurodevelopmental and behavioural outcomes at 24 months c.a (Bayley III, NSMDA, Toddler SP2, ITSEA).

\section{Aim 8}

To determine any predictive relationship between sensory processing profile (Infant SP2) at 16 weeks postterm and sensory processing or motor profile at 24 months c.a (Toddler SP2, Bayley III).

\section{Hypotheses}

H8a. A typical sensory processing profile at 16 weeks post-term on the Infant SP2 (infant total score $<1 \mathrm{SD}$ from the mean) will remain stable over time and predict a typical sensory profile at 24 months c.a on the Toddler SP2.

$H 8 b$. An atypical sensory processing profile at 16 weeks post-term on the Infant SP2 (infant total score $>2$ SD from the mean) will be associated with an atypical sensory profile at 24 months c.a on the Toddler SP2 (scores $>$ 2SD from the mean in any quadrant, sensory or behavioural domain).

H8c. An atypical sensory processing profile at 16 weeks post-term on the Infant SP2 (infant total score $>2 \mathrm{SD}$ away from the mean) will be associated with motor delay at 24 months c.a on the Bayley III (motor composite score $1 \mathrm{SD}$ or more below the mean). 
Table 1 Predictive values of GMs, NPV and PPV, with respect to neurodevelopmental outcome between 18 and 24 months corrected age

\begin{tabular}{|c|c|c|c|c|c|c|c|}
\hline $\begin{array}{l}\text { Studies } \\
\text { included }\end{array}$ & $\begin{array}{l}\text { Sample } \\
\text { size }(n)\end{array}$ & Participants & $\begin{array}{l}\text { Outcome measure and } \\
\text { age at outcome }\end{array}$ & $\begin{array}{l}\text { Preterm } \\
\text { NPV (\%) }\end{array}$ & $\begin{array}{l}\text { Post-term } \\
\text { NPV (\%) }\end{array}$ & $\begin{array}{l}\text { Preterm } \\
\text { PPV (\%) }\end{array}$ & $\begin{array}{l}\text { Post-term } \\
\text { PPV (\%) }\end{array}$ \\
\hline $\begin{array}{l}\text { Stahlmann } \\
\text { et a }{ }^{63}\end{array}$ & 103 & $\begin{array}{l}\text { Preterm } \\
\text { infants } \\
<1500 \mathrm{~g}\end{array}$ & $\begin{array}{l}\text { Motor outcome on the } \\
\text { Griffiths Developmental } \\
\text { Motor Scale at } \\
20 \text { months }\end{array}$ & & *84 & & *89 \\
\hline $\begin{array}{l}\text { Constantinou } \\
\text { et } a \rho^{4}\end{array}$ & 102 & $\begin{array}{l}\text { Preterm } \\
\text { infants } \\
<1500 \mathrm{~g}\end{array}$ & $\begin{array}{l}\text { Neurological } \\
\text { examination and Bayley } \\
\text { II scores at } 18 \text { months }\end{array}$ & 90 & ${ }^{*} 90$ & 29 & *41 \\
\hline Spittle et $a^{\rho^{5}}$ & 94 & $\begin{array}{l}\text { Preterm } \\
\text { infants } \\
<30 \text { weeks }\end{array}$ & $\begin{array}{l}\text { Cognitive outcome on } \\
\text { the Bayley III at } 2 \text { years } \\
\text { Language outcome on } \\
\text { the Bayley III at } 2 \text { years } \\
\text { Motor outcome on the } \\
\text { Bayley III at } 2 \text { years }\end{array}$ & & $\begin{array}{l}\dagger 94 * 96 \\
\dagger 91{ }^{*} 93 \\
\dagger 100{ }^{*} 96\end{array}$ & & $\begin{array}{l}\dagger 14 * 35 \\
+14 * 35 \\
+16 * 35\end{array}$ \\
\hline
\end{tabular}

\section{METHODS}

\section{Participants}

Participants will be a prospective cohort of infants born at $<32$ weeks and/or $<1500 \mathrm{~g}$ admitted to the Special Care Nursery (SCN), Nambour General Hospital (NGH). Over a period of 24-36 months, 90 infants will be entered into the study.

\section{Inclusion criteria}

Infants born at $<1500 \mathrm{~g}$ and or $<32$ weeks gestation who are admitted to the SCN and can be recruited prior to 37 weeks g.a.

\section{Exclusion criteria}

- Infants with major congenital or chromosomal abnormalities.

- Families living outside a $100 \mathrm{~km}$ radius from the NGH.

- Families where no English is spoken.

\section{Sample size}

The primary aim of this study is to use longitudinal trajectories of GMs from 34 to 35 weeks gestation until 16 weeks post-term to predict typical or delayed neurodevelopmental outcome at 2 years c.a in very preterm/ VLBW infants. The GM Assessment was chosen as it is the 'gold standard' measure for prediction of neurodevelopmental outcome in this population. ${ }^{60}$

The expected ratio of normal to non-normal GMs assessments is 3:1. This figure is derived from pilot data collected in clinical practice at NGH, where a clinical cohort of 86 preterm infants $<32$ weeks and/or $<1500 \mathrm{~g}$ was assessed using GMs at 34-35 weeks g.a and then at $2,5,11-12$ and 16 weeks post-term. Fifty-nine infants had normal GMs at each time point compared with 21 infants with at least one abnormal finding in their assessment trajectory. Four infants were lost to follow-up.

The ability of GMs to predict neurodevelopmental outcome (typical/delayed) was determined by calculating mean negative and positive predictive values (NPV and PPV) from published studies with similar participant characteristics and outcome measures. Two recent systematic reviews evaluating the predictive validity of the GM Assessment were searched to find studies with comparable participants, measures and age at outcome. ${ }^{61} 62$ Only two studies with similar attributes were identified. ${ }^{63}{ }^{64} \mathrm{~A}$ third study, identified in additional searches, was also included ${ }^{65}$ (table 1 ).

Mean NPV and PPV were compared at each predictive time point (preterm, writing and fidgety age; table 2). The PS-Power and Sample Size Calculation Software V.3.1.2, 2014 was then used to generate the sample size calculations for preterm, writhing and fidgety ages using $\alpha 0.01$, power of 0.95 and a ratio of 3:1.

Results suggest that the predictive time point of fidgety age (8-20 weeks) will require the largest sample size to identify a statistically significant association between GMs and neurodevelopmental outcome. Data from the literature indicates that a normal GM result at

Table 2 Mean negative and positive predictive values using GMs at three time points to predict typical or delayed neurodevelopmental outcome in the second year of life

\begin{tabular}{lll}
\hline Time point & Mean NPV & Mean PPV \\
\hline Preterm & 90 & 29 \\
2-7 weeks post-term-writhing & 95 & 15 \\
8-20 weeks post-term-fidgety & 92 & 47 \\
\hline
\end{tabular}

GMs, General Movements; NPV, negative predictive value; PPV, positive predictive value. 
fidgety age leads to typical neurodevelopmental outcome at 24 months c.a in $92 \%$ of infants. Assuming that GMs at fidgety age correctly identify mild neurodevelopmental outcomes at 24 months c.a in $47 \%$ of occasions, we will need to collect data on 80 participants at 24 months c.a (20 with abnormal GM assessment and 60 with normal GM assessment) to demonstrate a statistically significant association between GM results at fidgety age and TD and MDD at 24 months c.a.

By the nature of their design, longitudinal cohort studies are vulnerable to participant attrition and missing data; a potential cause of bias. ${ }^{66}$ In order to minimise any possible impact we will add an extra 10 participants $(12.5 \%)$ into our study design and recruit a total of 90 infants into the PREMTiME study.

\section{Recruitment process}

Infants will be enrolled in the study between 34 and 36 weeks g.a. An administrative staff member in the SCN, not affiliated with the research project, will introduce the study to parents or caregivers of infants who meet eligibility criteria. If families are interested and provide permission for contact, the principal investigator or a member of the research team will supply a full information pack including the parent information statement. When providing the pack, a researcher, not associated with the infant's clinical care, will explain the study in more detail and answer all parent questions before seeking informed consent for study participation. Once signed consent is obtained, the infant will be enrolled in the study, parents will complete the relevant forms and questionnaires, and the infant will receive the relevant assessments.

\section{Data collection methods}

Data collection will start following consent and enrolment (see figure 1 for study timeline). Perinatal data will be collected by a member of the research team. Primary caregivers will complete baseline questionnaires: the EPDS, SRI and IOF-G.

Should a parent/caregiver score above 9 points on the EPDS, a member of the research team will refer the mother/caregiver to the SCN social worker. The social worker will discuss the results with the parent/caregiver, provide information about postnatal depression, explain the need for further monitoring and request consent to send a letter of notification to the carer's general practitioner (GP). Both the assessment findings and the follow-up plan will be documented in the mother's hospital chart. An opportunity to monitor progress is embedded within the study design. All mothers or primary caregivers will repeat the test when their infant reaches 45 weeks post-term.

Between 34 and 36 weeks g.a infants will be assessed in the SCN using the P-NE and the GM Assessment. All assessors will be masked to the identity, and medical history of the infants. GMs and PN-E assessments will be recorded using procedural guidelines developed by the research team. The clinical photographer at NGH is trained in the use of these guidelines. GM assessments will be viewed and scored offline by two to four assessors trained by the GM Trust.

After discharge, baseline data collection will occur during four return appointments to the Allied Health Paediatric Outpatient Clinic, NGH. At each visit, growth trajectories will be monitored by recording body weight and length. GMs will be videotaped by the NGH clinical photographer while supervised by a member of the research team and then viewed offline by expert assessors masked to the infant's identity, medical history, perinatal data and previous assessment findings. The visits will be timed for 2, 5, 11-12 and 16 weeks post-term providing an opportunity for repeat assessment of GMs during both the writhing and fidgety age. This may reduce the potential impact of missing data in the writhing age when infants are occasionally too unsettled to complete video assessment. Importantly, it meets the requirement for assessment of fidgety movement on at least two occasions to definitively classify GMs as absent fidgety. ${ }^{67}$

Additional data collection will occur at the 2, 5 and 16 weeks post-term appointments. At 2 weeks post-term, infants will complete the NNNS. The assessment will be administered by an NNNS accredited trainer masked to the identity and medical history of the infant. The assessment will be videotaped to allow offline scoring as appropriate.

At 5 weeks post-term, the primary caregivers will repeat the EPDS questionnaire. Should the caregiver score above 9 on this occasion, a social worker will be on site to discuss the results in session. The social worker will recommend that the mother/caregiver seek follow-up and consent will be sought to provide the GP with the assessment findings. The assessment results and negotiated health plan will be documented in the hospital chart.

At 16 weeks post-term, an occupational therapist will explain the Infant SP2 and provide parents with a copy of the questionnaire to complete in session. A physiotherapist will then administer the AIMS. Video footage collected during the 16-week visit will include both the GMs and the AIMS assessment allowing masked assessors to view and score the assessments offline. Following the 16-week post-term appointment, infants will be categorised according to longitudinal trajectories of GMs into low-risk, moderate-risk and highrisk groups (table 3).

The outcome of all baseline assessments will be forwarded in report format to the Paediatric Specialist Outpatient Clinic, NGH, where a consulting paediatrician will review all infants enrolled in the research project between 18 and 20 weeks post-term. At this visit, the paediatrician will have an opportunity to discuss baseline assessment findings with parents or caregivers. $\mathrm{He} /$ she may initiate referral to early intervention services and organise any additional medical investigations required. A request for MRI will be ordered by the 


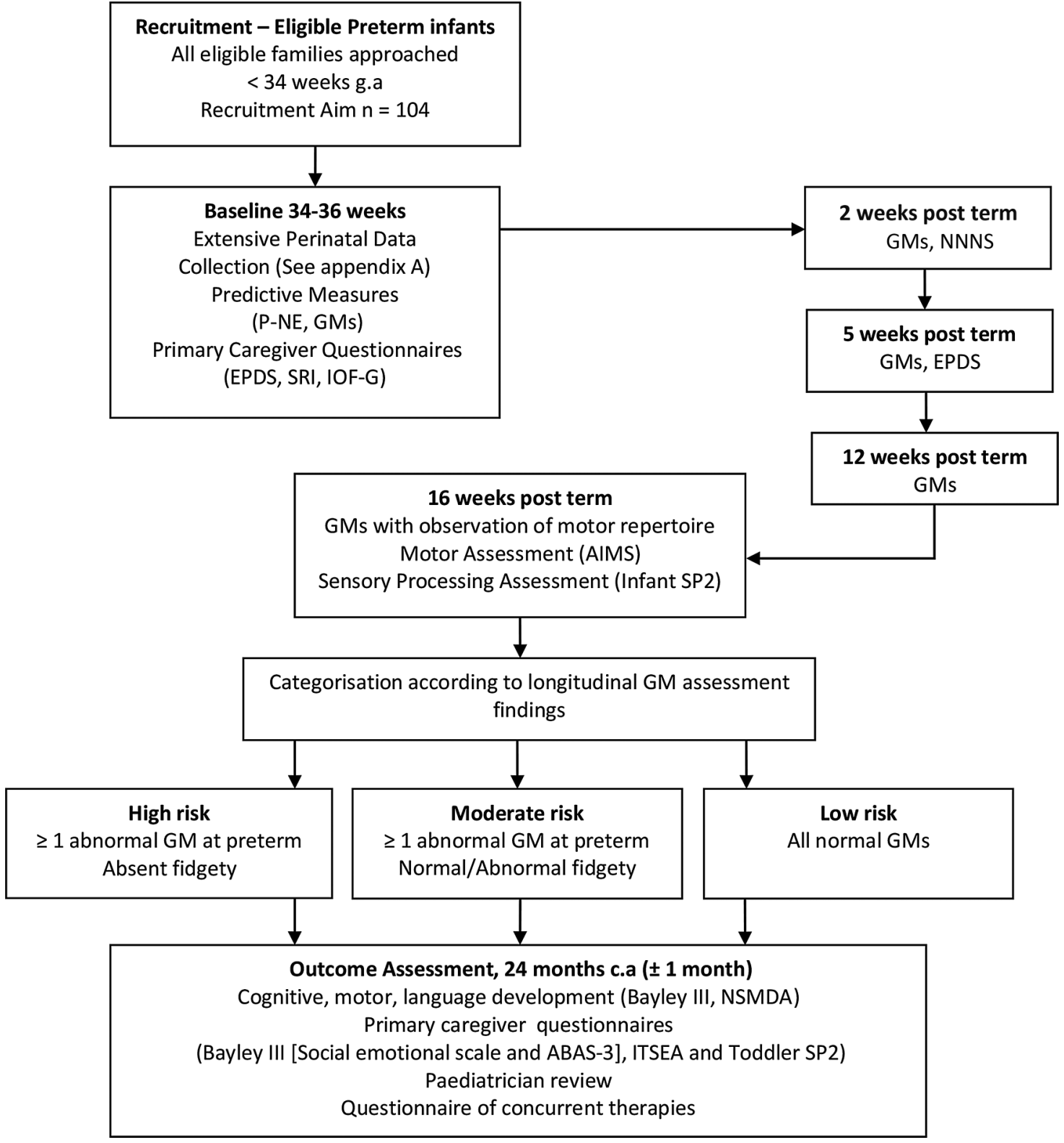

Figure 1 Study time line of recruitment and assessment time points. P-NE, the Premie-Neuro Examination; ${ }^{49} 51$ g.a, gestational age; GMs, General Movements Assessment; ${ }^{91}$ EPDS, Edinburgh Post Natal Depression Scale; ${ }^{84}$ SRI, Social Risk Index; ${ }^{12} 74$ IOF, Impact of Family Scale; ${ }^{87-89}$ NNNS, Neonatal Intensive Care Unit Network Neurobehavioral Scale; ${ }^{52}$ Infant SP2, Infant Sensory Profile 2,56 ${ }^{57}$ AIMS, Alberta Infant Motor Scale, ${ }^{100}$ Bayley III, Bayley Scales of Infant and Toddler Development-Third Edition; ${ }^{109}$ NSMDA, Neuro-Sensory and Motor Developmental Assessment; ${ }^{59}$ ITSEA, Infant-Toddler Social Emotional Assessment; ${ }^{119}$ Toddler SP2, Toddler Sensory Profile 2; ${ }^{56}$ ABAS III, Adaptive Behaviour Assessment Scale-Third Edition; ${ }^{116}$ c.a, corrected age.

paediatrician in cases where infants are assessed as absent fidgety on the GMs at 12 and 16 weeks.

Multidisciplinary case conferencing with the allied health team will be organised for all infants identified as high risk. The content and intensity of any concurrent therapy received while enrolled in the PREMTiME project will be documented by parents/caregivers in a study calendar and measured in a parent recall questionnaire provided at study completion.

At 24 months c.a $( \pm 1$ month), all participants will attend two final appointments at NGH. Approximately
4 weeks prior, families participating in the study will receive an appointment letter and the Toddler SP2 questionnaire to complete and return at the first appointment. Appointments will be scheduled within a 2-week period. Children will be assessed by examiners masked to the child's identified level of risk, previous assessment findings, medical history and perinatal data.

At the first appointment, children will receive the cognitive, motor and language scales of the Bayley III and the Toddler SP2 questionnaire will be scored. Caregivers will be provided with the ITSEA to complete at home 
Table 3 Classification of neurodevelopmental risk according to trajectory of longitudinal GMs between 34-35 weeks g.a and 16 weeks post-term

\begin{tabular}{ll}
\hline $\begin{array}{l}\text { Level of } \\
\text { risk }\end{array}$ & Method of classification \\
\hline Low & $\begin{array}{l}\text { All normal GMs at preterm, writhing and } \\
\text { fidgety age }\end{array}$ \\
& $\begin{array}{l}\text { At least one finding of abnormal movement } \\
\text { (poor repertoire or cramped synchronised) at } \\
\text { preterm or writhing age combined with either } \\
\text { normal fidgety or abnormal fidgety movement } \\
\text { at fidgety age. }\end{array}$ \\
& $\begin{array}{l}\text { At least one finding of abnormal movement } \\
\text { (poor repertoire or cramped synchronised) at } \\
\text { preterm or writhing period combined with } \\
\text { absent fidgety movement at fidgety age. }\end{array}$ \\
\hline
\end{tabular}

and return at the second session. Height and weight measurements will be recorded.

At the second visit, parent/caregivers will complete the Adaptive Behaviour Scales (ABAS III) and the Social Emotional Scales of the Bayley III while a member of the research team administers the NSMDA. Both the Bayley III and NSMDA assessments will be video recorded by the NGH clinical photographer.

All results of outcome assessment will be forwarded to the child's paediatrician at NGH, Paediatric Specialist Outpatient Department. The paediatrician will review each child within 1 month of study completion. At this visit, final study results will be conveyed to the parents/ caregivers. Any diagnosis of CP will be documented, defined and classified according to the Surveillance of CP in Europe Network Guidelines and the Gross Motor Function Classification Scale (GMFCS) ${ }^{68-72}$ Classification of motor type of CP and GMFCS will be confirmed after review of video footage of the NSMDA by independent expert assessors at the Queensland Cerebral Palsy and Rehabilitation Research Centre (QCPRRC). ${ }^{69} 73$

\section{MEASURES AND PROCEDURES \\ Baseline measures \\ Perinatal data}

An extensive record of antenatal and birth history and the neonatal course will be collected from the Nambour Hospital medical file at enrolment and then at discharge from the SCN. ${ }^{74}$ Data collected will include primary perinatal factors with known associations with neurodevelopmental delay including early brain injury (intraventricular haemorrhage identified on CUS or brain injury identified on MRI), IUGR (weight $<10$ th centile for g.a), BPD (definition for infants born at $<32$ weeks g.a as per criteria outlined by the National Institute for Health, USA), ROP (classified by stages 1-5), severe NEC (requiring surgery), late-onset sepsis (onset $>48$ hours postbirth), preterm premature rupture of membranes, postnatal infant steroid therapy and g.a at birth. ${ }^{19-11} 76-82$

$\mathrm{NGH}$ is a regional facility located $100 \mathrm{~km}$ north of the nearest neonatal intensive care unit. Only a portion of high-risk babies born or transferred from the Royal Brisbane and Women's Hospital (RBWH) will receive MRI prior to transfer to Nambour. A summary of MRI assessment findings will be included in transfer documentation and will be collected with perinatal data when possible. All very preterm/VLBW infants will have routine CUS at days 3, 7 and 42 of life at the RBWH prior to transfer to NGH. Early CUS findings are routinely included in transfer documentation and graded and reported according to the conventions outlined in the Australia and New Zealand Neonatal Network (ANZNN) data dictionary ${ }^{83}$ (see online supplementary appendix 1 for a complete list of all perinatal variables included in data collection).

\section{Primary caregiver information}

\section{Edinburgh Post Natal Depression Scale}

The EPDS is used to screen primary caregivers for risk of postnatal depression. It is a 10-item self-reported scale that takes 5 min to administer. ${ }^{84}$ Originally implemented in the UK, it has since been validated for use in Australia, demonstrating high sensitivity (100\%) and specificity $(89 \%)$ at a cut-off score of $12.5 .{ }^{85}$ The EPDS appears to be acceptable to women as a screening instrument with no complaints reported in an Australian study of 4148 administrations carried out over 3 years. ${ }^{86}$ Facilitation of correct diagnosis is optimised by a two-step strategy where those scoring above a predetermined cut-off score on the first occasion have another test readministered at a subsequent health visit. ${ }^{86}$ In keeping with this evidence-based recommendation, the EPDS will be used twice during this study. Primary caregivers will complete the questionnaire at 34-36 weeks and at 5 weeks post-term.

Clearly defined processes have been developed around the event that a parent/caregiver scores above a clinically conservative score of 9 points on the scale. Researchers will ensure that caregivers are provided timely support by a social worker, consent is sought to inform their GP, women are encouraged to seek follow-up and a negotiated health plan is documented in the hospital chart.

\section{Social Risk Index}

A 12-point SRI will be used between 34 and 36 weeks g.a to provide an overall social risk score for each family. ${ }^{12}{ }^{74}$ Families will be informed in the parent information statement that all responses on the questionnaire will be treated in a strictly confidential manner. The index measures six aspects of social status:

1. Family structure (0-two caregivers (nuclear); 1separated parents with dual custody, or cared for by other intact family; 2-single caregiver); 
2. Education of primary caregiver $(0-$ tertiary educated; $1-11-12$ years of formal schooling; $2-<11$ years of formal schooling);

3. Occupation of primary income earner ( 0 -skilled/ professional; 1-semiskilled; 2-unskilled);

4. Employment status of primary income earner (0-full-time employment; 1-part-time employment; 2-unemployed/pension);

5. Language spoken at home (0-English only; 1-some English; 2-no English);

6. Maternal age at birth (0-more than 21 years; $1-18$ 21 years; $2-<18$ years .

Families will be categorised as lower social risk (score $\leq 1)$ or higher social risk $(\geq 2) .^{74}$

\section{Revised IOF-G Scale}

This questionnaire will be used between 34 and 36 weeks to assess the effect of a child's illness, in this case preterm birth, on the family system. The scale is an easily administered, reliable and valid measure of a family member's perception of the effect of a child's chronic condition that can be used across diagnostic groups. ${ }^{87-89}$ There are 15 items scored on a four-point Likert scale (strongly agree to strongly disagree) that take $10 \mathrm{~min}$ to complete. It can be used either as a questionnaire or read to the family if needed. ${ }^{87-89}$

\section{Infant assessments}

\section{The Premie-Neuro Examination}

The PN-E is a new assessment tool designed in response to the relative scarcity of effective neurological assessments available for the extremely low birth weight and VLBW infant. ${ }^{49}{ }^{51}$ It is a standardised clinical neurological and neurobehavioural examination designed to assess brain function in fragile VLBW/very preterm infants from birth until 37 weeks of gestation. ${ }^{49}$ The test is specifically designed to minimise the impact of handling and can be modified for infants $<28$ weeks. It can be done while the baby is still in an isolette and electronically monitored and can be completed within $\sim 10 \mathrm{~min}$.

The test is administered between $30 \mathrm{~min}$ and 1 hour before a scheduled feed and takes 10-15 min to complete. It consists of three subscales: Neurological, Movement and Responsiveness-each with eight items. Early research indicates good construct validity with good internal consistencies of the three subscales (Cronbach's $\alpha$ 75, 0.73 and 0.82). There is evidence of predictive capability with raw scores at 34-36 weeks c.a able to discriminate between high-risk and low-risk groups of infants at term age and predict outcome on the AIMS at 3 months c.a. ${ }^{46} 4951$ In keeping with these findings infants in this study will have the PN-E administered between 34 and 36 weeks g.a.

It is acknowledged that the PN-E has less published evidence for prediction than other preterm assessments such as the Dubowitz Neurological Assessment or the Test of Infant Motor Performance (TIMP). The Dubowitz was not included in this study as its predictive capability for normal outcomes is relatively modest and the primary aim of this study is to predict typical outcome. ${ }^{90}$ The TIMP has moderately better predictive validity for outcome than the Dubowitz but less clinical utility than the PN-E. ${ }^{45}$ The TIMP takes up to $40 \mathrm{~min}$ to administer while scoring 42 items, the majority of which are elicited. This is not suited to many fragile preterm infants $<36$ weeks of age and does not fit well within the ethos of a SCN where nursing and medical staff aim to keep handling and cares to a bare minimum.

As the PN-E has high clinical utility with early indications of useful clinical validity, it has potential for use as a very early biomarker of neurodevelopmental risk. Further research is required to determine test reliability in the clinical setting, to determine concurrent validity with other early neuromotor assessments (specifically GMs) and to further determine predictive validity. ${ }^{51}$ All P-NE assessments will be video recorded to increase accuracy of measurement, especially on observational items. Our own inter-rater reliability will be determined as part of the study using a subsample of 20 infants.

\section{Prechtl's Method of Qualitative Assessment of GMs}

The GM Assessment is a predictive and discriminative tool that involves longitudinal observations of the infant's spontaneous motor activity. ${ }^{45} 91$ GMs have high specificity (96\%) and sensitivity (95\%) for predicting CP and early evidence suggests they have potential to predict normal or milder neurodevelopmental outcomes. ${ }^{61} 62$ 92-95 GMs are assessed from preterm until 20 weeks c.a. The assessment is carried out by videoing the infant in a calm alert state, without external stimulation. In the early preterm stage, this may require up to an hour of video recording but after the infant reaches term age, $5 \mathrm{~min}$ is the minimum requirement.

Examiners must determine if spontaneous movement is fluent, variable and complex before defining GMs as normal or abnormal. ${ }^{91}$ Normal GMs in the preterm period are gross movements involving the whole body, including arm, leg, neck and trunk movements in variable sequence. They 'wax and wane' in intensity, force and speed and have a gradual beginning and end. ${ }^{91}$ From 40 weeks until $\sim 8$ weeks post-term movements are classified as 'writhing' in nature. Normal writhing movements are characterised by small-to-moderate amplitude and by slow-to-moderate speed and are elliptical in form. Abnormal movements during the both the preterm and writing periods are described as poor repertoire, chaotic or cramped synchronised. ${ }^{91}$

Between 6 and 9 weeks post-term and continuing until $\sim 20$ weeks c.a, GMs change to a 'fidgety' pattern and are defined as "circular movements of small amplitude and moderate speed and variable acceleration, of neck, trunk, and limbs, in all directions". ${ }^{91}$ They are continual in the awake infant, except during focused attention, fussing and crying. The infant will score as normal when fidgety movements are present. Abnormal movement is 
scored when fidgety movements are absent or abnormal in pattern. Assessment at more than one time point during the fidgety age is necessary to definitively score an infant as absent fidgety. ${ }^{67}$ The infants in this study will have GMs assessed at 34-36, 2, 5, 11-12 and 16 weeks post-term.

\section{Neonatal Intensive Care Unit Network Neurobehavioral Scale}

The NNNS is a non-invasive clinical tool developed to assess neurobehaviour of 'at-risk' infants and is suitable for use with very preterm/VLBW infants. ${ }^{52} 96$ The assessment takes between 15 and 20 min to administer, ideally in a quiet, dimly lit room, 2 hours after feeding. The examination is state-dependent with a standardised format. It assesses the full range of infant neurobehavioral performance including neurological integrity, behavioural functioning and signs of stress/abstinence. ${ }^{52} 96$

Test items are presented in 13 packages providing summary scores/subscales for habituation, attention, handling, quality of movement, regulation, non-optimal reflexes, arousal, hypertonicity, hypotonicity, asymmetrical reflexes, excitability and lethargy. ${ }^{52} 96$ The NNNS has good internal consistency for item summary scores (Cronbach's $\alpha 0.87-0.90) .{ }^{97}$ Published norms are available for summary scores of healthy term-born infants at term age $(n=344)$ and for summary scores of very preterm infants at 1 month c.a $\left(n=204\right.$, 24-32 weeks g.a) ${ }^{97} 98$

Evidence for prediction of motor and cognitive outcomes in very preterm and VLBW populations is good. ${ }^{53} 54{ }^{99}$ Summary scores at term c.a in a sample of 41 VLBW infants were predictive of motor and cognitive outcomes on the Bayley Scales of Infant and Toddler Development-Second Edition (Bayley II) at 18 months c.a. ${ }^{53}$ In another study of 1248 infants $<37$ weeks gestation, profiles of summary scores (profiles 1-5) were calculated and used to predict outcome from birth to 4.5 years. At 1 month c.a, infants with a profile of five were more likely to have impaired Bayley II mental and psychomotor developmental index scores at 2 years c.a; chronic neurological abnormalities and brain-related illness or CP and behaviour problems at 3 years; motor, concept and language problems in school readiness at age 4 years; and lower IQ at 4.5 years. ${ }^{54}$ The NNNS will be used to assess infant neurobehaviour at 2 weeks c.a.

\section{Alberta Infant Motor Scale}

The AIMS is a discriminative, norm referenced tool that tests gross motor skills through the components of weight bearing, posture and antigravity movements. ${ }^{100} 101$ The test takes 20 min to administer and involves observation of the infant in prone, supine, sitting and standing. The AIMS is an appropriate assessment tool for monitoring the gross motor development of typically developing infants and has normative data based on a population of 2200 infants from 0 to 18 months in Alberta, Canada. ${ }^{102}$ Normative data for preterm infants has also been published with a sample of 800 infants born at $<32$ weeks from the Netherlands. ${ }^{103}$
The AIMS has excellent inter-rater, intra-rater and test-retest reliability for full-term and preterm infants. $^{104} 105$ The AIMS has excellent reliability, content, construct and concurrent validity with the BSID-II $(r=0.98) .^{100} 103105$ Although the AIMS was not designed as a predictive tool, it has good predictive validity at 4 months for developmental outcome at 18 months (sensitivity $77.3 \%$, specificity $81.7 \%$ ). ${ }^{106}$ The AIMS will be used to classify each infant's development as normal or suspicious/abnormal at 56 weeks g.a using cut points at the 10th centile on the term percentile scale and the 25th centile on the premature infant percentile scale. $^{100102}$

\section{Sensory Profile 2}

The SP2 is a newly revised edition of the ITSP. ${ }^{56}{ }^{57}$ It is a standardised tool used to evaluate a child's sensory processing patterns in the context of participation. It enables professionals to gather information about the child's sensory processing abilities and how those patterns either support or interfere with functional performance. ${ }^{58}$ It is based on a sensory integration and neuroscience frame of reference and the author's model of sensory processing. ${ }^{107} 108$

The tool supports family-centred practice by actively engaging the primary caregiver in the data gathering process. ${ }^{108}$ Primary caregivers observe the infant or child engaging in a number of different environmental contexts at home or other community settings and then report on a range of behaviours on the item scoring sheet. The estimated time for completion is 5-20 min based on the caregiver completing the questionnaire in one sitting.

The SP2 was standardised between 2012 and 2013 using a normative sample of 1791 participants and a clinical sample of $771 .^{56} 57$ Where previously only raw scores were calculated, the new version allows percentile ranking of infant total scores as well as quadrant scores for toddlers and older children. Reliability of the measure is overall good to very good (internal consistency 0.63-0.93, parent test-retest $0.83-0.97$, inter-rater reliability $0.49-0.9 /$ mostly $>0.7) .{ }^{56}$ Correlation between the ITSP and the SP2 is moderate-to-high. ${ }^{56} 57$

The new edition has several other improvements and advantages compared with the ITSP. ${ }^{56}$ The required reading level is grade 6 equivalent and parents have the option to complete the forms online. In addition, the questionnaire is now presented in two separate userfriendly forms for infants and for toddlers. The Infant SP2 is used for babies from birth to 6 months and will be used as a baseline measure at 16 weeks post-term. The Toddler SP2 is for ages 7-35 months. It will be used as an outcome measure at 24 months c.a.

\section{Outcome measures}

The Bayley Scales of Infant and Toddler DevelopmentThird Edition

This assessment is a relatively new revision of the Bayley II. It is a norm-referenced, discriminative measure used 
to describe the current developmental functioning of the infant with good to strong validity and reliability. ${ }^{109}$ Other possible uses of the test include identification of possible developmental delay, identification of relative strengths and weaknesses, monitoring of developmental progress and prediction of cognitive function at preschool entry. ${ }^{110}$ The third edition consists of five distinct scales: Cognitive, Language, Motor, Social-Emotional and ABAS II. All five scales will be utilised in this study. Assessment is individually administered and may take up to $90 \mathrm{~min}$ to complete. Caregivers are encouraged to remain present but not to influence the test proceedings.

Several recent studies recommend the precautionary use of a term-born control group and/or different cut points when using the Bayley III as a primary outcome measure. ${ }^{111-114}$ Studies conducted in Australia and the USA have found that significantly fewer infants are identified with neurodevelopmental delay with the Bayley III when compared with previous findings using the Bayley II. ${ }^{112} 113$ Several explanations are possible but it is still unclear whether the Bayley III is overestimating developmental performance, whether it is a more valid assessment of neurodevelopmental impairment than the Bayley II or if premature infant outcomes are improving. In keeping with these recommendations, scores obtained in this cohort of very preterm/VLBW infants will be compared with published reference data of an Australian cohort of 202 term-born controls. ${ }^{112}$

The ABAS II is one of the five subscales in the Bayley III. ${ }^{109}$ Adaptive behaviour is defined as the collection of conceptual, social and practical skills that have been learned by people in order to function in their everyday lives. ${ }^{115}$ A newly revised edition, the ABAS III is now available for use ${ }^{116}$ Retaining all of the essential features of the ABAS II, the new edition is even easier to administer and score. It is a parent-reported, norm-referenced and standardised measure of adaptive skills measuring a child's functioning ability in the areas of Communication, Community Use, Health and Safety, Leisure, Self-Care, Self-Direction, Functional Pre-Academics, Home or School Living, Social, Work and Motor.

The ABAS III takes 15-20 min to complete. Caregivers rate the extent to which their child performs the adaptive skill when needed using a four-point reference scale. Norm-referenced scaled scores are used to interpret results in the skills area and norm-referenced standard scores, CIs for standard scores, and percentile ranks are used to rate performance across the three adaptive domains and calculate a General Adaptive Composite Score. ${ }^{116}$ The ABAS III builds on the ABAS II which has strong psychometric properties with good to excellent content validity, test-retest reliability and internal consistency. ${ }^{115}$

\section{The Neuro-Sensory and Motor Developmental Assessment}

This a discriminative and predictive criterion referenced measure with a functional grading system that scores overall motor performance classification as normal, mild not impacting function, mild, moderate, severe or profound impairment. ${ }^{59} 117$ It measures gross motor, fine motor and sensory motor development, neurological status and postural control. The examiner observes and administers items and the test takes up to $30 \mathrm{~min}$ to complete. A published study of 148 preterm infants demonstrates adequate construct validity with the NSMDA able to discriminate between normal and abnormal outcome at 24 months c.a. ${ }^{45} 118$ Concurrent validity has been reported in relation to agreement with paediatric classification of normal or atypical development at 24 months c.a $\left(\chi^{2}=0.08\right){ }^{45}{ }^{118}$ Reliability has only been reported in terms of correlation $(\mathrm{r}=0.80) .{ }^{45}$

\section{The Infant Toddler Social-Emotional Assessment}

The ITSEA is a comprehensive parent-reported instrument for evaluating behavioural problems and social emotional competencies in infants aged 12-36 months. ${ }^{119}$ The complete ITSEA includes 166 items that are rated on a three-point scale: (0) not true/rarely, (1) somewhat true/sometimes and (2) very true/often. A 'no opportunity' code allows parents to indicate that they have not had the opportunity to observe certain behaviours. If reading levels are inadequate, it can be presented in interview format without impeding test reliability. ${ }^{119}$

The test measures four broad domains of behaviour: externalising, internalising, dysregulation and competencies. Three additional indices: maladaptive, atypical behaviour and social relatedness are used to aid identification of significant psychopathology including attention-deficit hyperactivity disorder or autistic spectrum disorder. ${ }^{119}$ Test construct, reliability and validity was examined in a population sample of 1235 parents of children. ${ }^{119}$ The test has good internal consistency across all four major domains, good validity, and acceptable test-retest and inter-rater reliability. ${ }^{45} 119$

\section{DATA ANALYSIS PLAN}

Analysis will be carried out using R V.2.9.1 with the R-Commander and R Studio statistical analysis packages. Predictor and outcome variables will be identified as continuous or categorical. Initial analysis will explore the distributions, means and variability of continuous variables and the rate of occurrence and distribution of categorical variables. Any outlying data will be identified and the characteristics of any missing data explored. Graphical representations (histograms, boxplots and scatter plots), tables of means and SD and cross tabulations will be used to understand any relationships between variables.

Univariable regression analysis will be used to determine any associations between predictor and outcome variables. A forward selection process, entering variables one-by-one, will help to determine any confounding pathways. Multivariable analysis will be performed to 
understand major contributors and the effect of confounders. Generalised estimating equations (GEEs) will be included to determine the extent that early assessment will predict later outcomes of interest. ${ }^{120}$ GEEs track the importance of potential predictor variables over time, accounting for the dependence of observations recorded from the same participant. Consideration will be given to any non-linear effects and interactions.

A scaled score of the baseline assessment measures will be used to determine the sensitivity, specificity, PPV and NPV of early biomarkers to predict typical outcome and MDD at 24 months c.a. Typical outcome will be defined as motor and cognitive scores that are above 1SD below the mean on the Bayley III and a functional grade of 1 or 2 on the NSMDA. Developmental delay will be defined as motor and cognitive scores 1SD or more below the mean on the motor and cognitive subscales of the Bayley III and a functional grade $>2$ on the NSMDA.

\section{DISCUSSION}

As families, clinicians and health services continue to want and need more immediate information regarding the short-term and long-term outcomes of at-risk infants, finding the best clinical biomarkers has the potential to streamline and effectively prioritise premature infant follow-up programmes.

Results of this study will inform health policy and service delivery of follow-up pathways and early intervention for very preterm/VLBW infants and their families and guide the provision of targeted, evidence-based service delivery in clinical settings. Findings will be of interest to medical, allied health, nursing staff, hospital and health service districts.

Findings will also inform future studies with the intent to follow this cohort of very preterm/VLBW infants until completion of the Queensland Studies Authority, Grade 2 Diagnostic NET test. The Diagnostic NET test is a monitoring and assessment programme of literacy and numeracy competencies administered state wide and typically undertaken at 7 years of age in Queensland schools. $^{121}$

\section{Author affiliations}

${ }^{1}$ Faculty of Medicine and Biomedical Science, School of Medicine, The University of Queensland, Queensland Cerebral Palsy and Rehabilitation Research Centre (QCPRRC), South Brisbane, Queensland, Australia ${ }^{2}$ Sunshine Coast Hospital and Health Service, Allied Health Women's and Families, Nambour General Hospital, Nambour, Queensland, Australia ${ }^{3}$ Faculty of Health Sciences, The University of Queensland, The University of Queensland Centre for Clinical Research, Royal Brisbane and Women's Hospital, Brisbane, Queensland, Australia

${ }^{4}$ Royal Brisbane and Women's Hospital, Herston, Queensland, Australia ${ }^{5}$ Department of Developmental Neuroscience, Stella Maris Scientific Institute, Pisa, Italy

${ }^{6}$ University of Queensland, School of Population Health, Herston, Queensland, Australia

${ }^{7}$ Department of Paediatrics, Sunshine Coast Hospital and Health Service, Nambour General Hospital, Nambour, Queensland, Australia
Acknowledgements The team acknowledges the contributions of administrative officers in the Women's and Families Stream NGH, for coordination of outpatient appointment bookings. It thanks Mr Geoffrey Eddy, Clinical Photographer, for video recording of research assessments. It also acknowledges assistance from Mrs Lorelle Addison and Mrs Helen Moffat, administrative officers in the NGH SCN, with study recruitment. It thanks Ms Megan Rutter, Research Governance and Development Manager at Nambour General Hospital for her assistance with ethics approval and grant applications.

Collaborators PREMTiME Study Group. Collaborators that have provided scientific advice: Susanne Cuddihy, Kellee Gee, Heidi Webster; collaborators who have provided assistance with patient care and data collection: Louise Tambling, Julie Creen.

Contributors RC, RNB, PC, GC and RSW are chief investigators who have had substantial input into study design. MJ, KS, JD and TH are associate investigators who have provided input into study design. RC, RNB, PC and GC are study personnel responsible for ethics applications and reporting. RC, RNB, PC, GC and RSW are study personnel responsible for writing the protocol manuscript. RC, KS, JD, MJ, LM, TH, AM, CT, LC and EB are study personnel responsible for recruitment, data collection and implementation of the study. RC, RNB, PC, GC and RSW are chief investigators who will take lead roles in publication of the clinical outcomes of the study. All authors have read and approved the final manuscript.

Funding The PREMTiME study is funded by grants from the Health Practitioner Research Grant Scheme, Queensland Health and by Wishlist, Sunshine Coast Health Foundation (Reference number: 2014-08). It receives support from Allied Health staff working in the Women's and Families stream at NGH including physiotherapists, occupational therapists, dieticians, social workers and speech pathologists. Further support is provided by administrative, nursing and medical staff in the NGH SCN, administrative staff at the Sunshine Coast Clinical School and from the Medical Imaging Department, Nambour General Hospital.

\section{Competing interests None declared.}

Ethics approval Ethical permission to conduct the study has been obtained from the Queensland Children's Health Services (RCH) Human Research Ethics Committee (HREC/13/QRCH/66), the University of Queensland (2013001019) and the Sunshine Coast Hospital and Health Service, SC-Research Governance (SSA/13/QNB/66). Publications of all outcomes will be in peer-reviewed journals.

Provenance and peer review Not commissioned; externally peer reviewed.

Data sharing statement Data collected at 2-year outcomes may be shared with three other studies when participants are enrolled in these studies concurrently: (1) The Magenta Trial-Magnesium sulphate at 30-34 weeks' gestational Age: Neuroprotection Trial, The University of Adelaide, SA, Australia. (2) The PREBO study, Queensland Cerebral Palsy and Rehabilitation Research Centre, The University of Queensland, QLD, Australia. (3) The Developmental Assessment Program (DAP), Royal Brisbane Women's Hospital, QLD, Australia.

Open Access This is an Open Access article distributed in accordance with the Creative Commons Attribution Non Commercial (CC BY-NC 4.0) license, which permits others to distribute, remix, adapt, build upon this work noncommercially, and license their derivative works on different terms, provided the original work is properly cited and the use is non-commercial. See: http:// creativecommons.org/licenses/by-nc/4.0/

\section{REFERENCES}

1. Saigal S, Doyle LW. An overview of mortality and sequelae of preterm birth from infancy to adulthood. Lancet 2008;371:261-9.

2. Doyle LW. Evaluation of neonatal intensive care for extremely-lowbirth-weight infants. Semin Fetal Neonatal Med 2006;11: 139-45.

3. Moore T, Hennessy EM, Myles J, et al. Neurological and developmental outcome in extremely preterm children born in England in 1995 and 2006: the EPICure studies. Obstet Anesth Dig 2014;34:37-8. 
4. de Kieviet JF, Piek JP, Aarnoudse-Moens CS, et al. Motor development in very preterm and very low-birth-weight children from birth to adolescence: a meta-analysis. JAMA 2009;302:2235-42.

5. Doyle L, Roberts G, Anderson PJ. Outcomes at age 2 years of infants <28 weeks' gestational age born in Victoria in 2005. $J$ Pediatr 2010;156:49-53.e1.

6. Kerstjens JM, de Winter AF, Bocca-Tjeertes IF, et al. Risk of developmental delay increases exponentially as gestational age of preterm infants decreases: a cohort study at age 4 years. Dev Med Child Neurol 2012;54:1096-101.

7. Van Hus JM, Potharst ES, Jeukens-Visser M, et al. Motor impairment in very preterm-born children: links with other developmental deficits at 5 years of age. Dev Med Child Neurol 2014;56:587-94.

8. Williams J, Lee KJ, Anderson PJ. Prevalence of motor-skill impairment in preterm children who do not develop cerebral palsy: a systematic review. Dev Med Child Neurol 2010;52:232-7.

9. Orcesi S, Olivieri I, Longo S, et al. Neurodevelopmental outcome of preterm very low birth weight infants born from 2005 to 2007. Eur J Paediatr Neurol 2012;16:716-23.

10. Schlapbach LJ, Adams M, Proietti E, et al. Outcome at two years of age in a Swiss national cohort of extremely preterm infants born between 2000 and 2008. BMC Pediatr 2012;12:198.

11. Moore T, Hennessy EM, Myles J, et al. Neurological and developmental outcome in extremely preterm children born in England in 1995 and 2006: the EPICure studies. BMJ 2012;345: e7961.

12. Roberts G, Howard K, Spittle AJ, et al. Rates of early intervention services in very preterm children with developmental disabilities at age 2 years. J Paediatr Child Health 2008;44:276-80.

13. Bhutta AT, Cleves MA, Casey PH, et al. Cognitive and behavioral outcomes of school-aged children who were born preterm: a meta-analysis. JAMA 2002;288:728-37.

14. Edwards J, Berube M, Erlandson K, et al. Developmental coordination disorder in school-aged children born very preterm and/or at very low birth weight: a systematic review. J Dev Behav Pediatr 2011;32:678-87.

15. Rogers C, Anderson P, Thompson D, et al. Regional cerebral development at term relates to school-age social-emotional development in very preterm children. J Am Acad Child Adolesc Psychiatry 2012:51:181-91.

16. Wild KT, Betancourt LM, Brodsky NL, et al. The effect of socioeconomic status on the language outcome of preterm infants at toddler age. Early Hum Dev 2013;89:743-6.

17. Als H, Duffy FH, McAnulty GB, et al. Early experience alters brain function and structure. Pediatrics 2004:113:846-57.

18. Estep ME, Smyser CD, Anderson PJ, et al. Diffusion tractography and neuromotor outcome in very preterm children with white matter abnormalities. Pediatr Res 2014;76:86-92.

19. Spittle AJ, Cheong J, Doyle LW, et al. Neonatal white matter abnormality predicts childhood motor impairment in very preterm children. Dev Med Child Neurol 2011;53:1000-6.

20. Greene MM, Patra K, Nelson MN, et al. Evaluating preterm infants with the Bayley-III: patterns and correlates of development. Res Dev Disabil 2012;33:1948-56.

21. Månsson J, Stjernqvist K. Children born extremely preterm show significant lower cognitive, language and motor function levels compared to children born at term, as measured by the Bayley-III at 2.5 years. Acta Paediatr 2014;103:504-11.

22. van der Pal-de Bruin KM, van der Pal SM, Verloove-Vanhorick SP et al. Profiling the preterm or VLBW born adolescent; implications of the Dutch POPS cohort follow-up studies. Early Hum Dev 2015;91:97-102.

23. Aarnoudse-Moens CSH, Weisglas-Kuperus N, van Goudoever JB, et al. Meta-analysis of neurobehavioral outcomes in very preterm and/or very low birth weight children. Pediatrics 2009;124: 717-28.

24. Eeles AL, Anderson PJ, Brown NC, et al. Sensory profiles obtained from parental reports correlate with independent assessments of development in very preterm children at 2 years of age. Early Hum Dev 2013;89:1075-80.

25. Volpe JJ. Brain injury in premature infants: a complex amalgam of destructive and developmental disturbances. Lancet Neurol 2009:8:110-24.

26. de Kieviet JF, Zoetebier L, van Elburg RM, et al. Brain development of very preterm and very low-birthweight children in childhood and adolescence: a meta-analysis. Dev Med Child Neurol 2012;54:313-23

27. Buonocore G, Perrone S, Bracci R. Free radicals and brain damage in the newborn. Biol Neonate 2001;79:180-6.
28. Agamanolis D. Chapter 3 Perinatal Ischaemia and Stroke Secondary Chapter 3 Perinatal Ischaemia and Stroke. 2010. http:// neuropathology-web.org/chapter3/chapter3dGmh.html

29. de Kieviet JF, Pouwels PJW, Lafeber HN, et al. A crucial role of altered fractional anisotropy in motor problems of very preterm children. Eur J Paediatr Neurol 2014;18:126-33.

30. Kelly CE, Chan L, Burnett AC, et al. Brain structural and microstructural alterations associated with cerebral palsy and motor impairments in adolescents born extremely preterm and/or extremely low birthweight. Dev Med Child Neurol 2015;57:1168-75.

31. Diamond A. Close interrelation of motor development and cognitive development and of the cerebellum and prefrontal cortex. Child Dev 2000;71:44-56.

32. Saalmann YB, Kastner S. Cognitive and perceptual functions of the visual thalamus. Neuron 2011;71:209-23.

33. Ostendorf F, Liebermann D, Ploner CJ. A role of the human thalamus in predicting the perceptual consequences of eye movements. Front Syst Neurosci 2013;7:10.

34. Mitchell AS, Chakraborty S. What does the mediodorsal thalamus do? Front Syst Neurosci 2013;7:37.

35. Prevosto V, Sommer MA. Cognitive control of movement via the cerebellar-recipient thalamus. Front Syst Neurosci 2013;7:56.

36. Owen JP, Marco EJ, Desai S, et al. Abnormal white matter microstructure in children with sensory processing disorders. Neuroimage Clin 2013;2:844-53.

37. Klostermann F. Functional roles of the thalamus for language capacities. Front Syst Neurosci 2013;7:32.

38. World Health O. ICF: International Classification of Functioning, Disability and Health/World Health Organization. Geneva: World Health Organization, 2001

39. Voss $\mathrm{W}$, Jungmann $\mathrm{T}$, Wachtendorf $\mathrm{M}$, et al. Long-term cognitive outcomes of extremely low-birth-weight infants: the influence of the maternal educational background. Acta Paediatr 2012;101:569-73.

40. Cserjesi R, Van Braeckel KNJA, Timmerman M, et al. Patterns of functioning and predictive factors in children born moderately preterm or at term. Dev Med Child Neurol 2012;54:710-15.

41. Mehler K, Mainusch A, Hucklenbruch-Rother E, et al. Increased rate of parental postpartum depression and traumatization in moderate and late preterm infants is independent of the infant's motor repertoire. Early Hum Dev 2014;90:797-801.

42. Treyvaud K, Lee KJ, Doyle LW, et al. Very preterm birth influences parental mental health and family outcomes seven years after birth. J Pediatr 2014;164:515-21.

43. Strimbu K, Tavel JA. What are biomarkers? Curr Opin HIV AIDS 2010;5:463-6.

44. Mandal A. Biomarker-What is a Biomarker? Secondary Biomarker -What is a Biomarker? http://www.news-medical.net/health/ Biomarker-What-is-a-Biomarker.aspx.

45. Spittle AJ, Doyle LW, Boyd RN. A systematic review of the clinimetric properties of neuromotor assessments for preterm infants during the first year of life. Dev Med Child Neurol 2008;50:254-66

46. Gagnon KL. Reliability and validity of the Premie-Neuro in detecting early neurodevelopmental delay and disability in preterm infants. [Ph.D.]. University of Kansas, 2009.

47. El-Dib M, Massaro AN, Glass P, et al. Neurodevelopmental assessment of the newborn: an opportunity for prediction of outcome. Brain Dev 2011;33:95-105.

48. Noble $\mathrm{Y}$, Boyd R. Neonatal assessments for the preterm infant up to 4 months corrected age: a systematic review. Dev Med Child Neurol 2012:54:129-39.

49. Daily DK, Ellison PH. The Premie-Neuro: a clinical neurologic examination of premature infants. Neonatal Netw 2005;24:15-22.

50. Scherzer AL, Chhagan M, Kauchali S, et al. Global perspective on early diagnosis and intervention for children with developmental delays and disabilities. Dev Med Child Neurol 2012;54:1079-84.

51. Gagnon KPPT, Cannon SMSPT, Weatherstone KBMD. The Premie-Neuro: opportunities and challenges for standardized neurologic assessment of the preterm infant. Adv Neonatal Care 2012;12:310-17.

52. Lester BM, Tronick EZ. History and description of the Neonatal Intensive Care Unit Network Neurobehavioral Scale. Pediatrics 2004;113(Pt 2):634-40.

53. El-Dib M, Massaro AN, Glass P, et al. Neurobehavioral assessment as a predictor of neurodevelopmental outcome in preterm infants. J Perinatol 2012;32:299-303.

54. Liu J, Bann C, Lester B, et al. Neonatal neurobehavior predicts medical and behavioral outcome. Pediatrics 2010;125:e90-8.

55. Sucharew H, Khoury JC, Xu Y, et al. NICU network neurobehavioral scale profiles predict developmental outcomes in a low-risk sample. Paediatr Perinat Epidemiol 2012;26:344-52. 
56. Cooper M. Introduction and Overview of the Sensory Profile 2. Secondary Introduction and Overview of the Sensory Profile 2. Pearson Clinical Assessment Webinar Archive 2014. http://mfile. akamai.com/23543/wmv/citrixvar.download.akamai.com/23543/ www/442/808/8068365212672442808/3-8068365212672442808147478595 dc.asx?

57. Dunn W. The sensory profile 2: manual. San Antonio, TX: The Psychological Corporation, 2014.

58. Eeles AL, Spittle A, Anderson P, et al. Assessments of sensory processing in infants: a systematic review. Dev Med Child Neurol 2013;55:314-26

59. Burns Y. NSMDA: physiotherapy assessment for infants and young children. Brisbane: Copyright Publishing Co Pty Ltd, 1992.

60. Bosanquet M, Copeland L, Ware R, et al. A systematic review of tests to predict cerebral palsy in young children. Dev Med Child Neurol 2013;55:418-26.

61. Burger M, Louw QA. The predictive validity of general movements —a systematic review. Eur J Paediatr Neurol 2009;13:408-20.

62. Darsaklis V, Snider LM, Majnemer A, et al. Predictive validity of Prechtl's Method on the Qualitative Assessment of General Movements: a systematic review of the evidence. Dev Med Child Neurol 2011;53:896-906

63. Stahlmann N, Härtel C, Knopp A, et al. Predictive value of neurodevelopmental assessment versus evaluation of general movements for motor outcome in preterm infants with birth weights $<1500$ g. Neuropediatrics 2007:38:91-9.

64. Constantinou JC, Adamson-Macedo EN, et al. Movement, imaging and neurobehavioral assessment as predictors of cerebral palsy in preterm infants. J Perinatol 2007;27:225-9.

65. Spittle AJ, Spencer-Smith MM, Cheong JLY, et al. General movements in very preterm children and neurodevelopment at 2 and 4 years. Pediatrics 2013;132:e452-8.

66. Mann CJ. Observational research methods. Research design II: cohort, cross sectional, and case-control studies. Emerg Med $J$ 2003;20:54-60.

67. Adde L, Helbostad J, Jensenius AR, et al. Identification of fidgety movements and prediction of CP by the use of computer-based video analysis is more accurate when based on two video recordings. Physiother Theory Pract 2013;29:469-75.

68. Smithers-Sheedy H, Badawi N, Blair E, et al. What constitutes cerebral palsy in the twenty-first century? Dev Med Child Neurol 2014;56:323-8.

69. Cans C. Surveillance of cerebral palsy in Europe: a collaboration of cerebral palsy surveys and registers. Surveillance of Cerebral Palsy in Europe (SCPE). Dev Med Child Neurol 2000;42:816-24.

70. Palisano R, Rosenbaum P, Bartlett D, et al. GMFCS-E \& R Gross Motor Function Classification System Expanded and Revised. Secondary GMFCS-E \& R Gross Motor Function Classification System Expanded and Revised. 2007. http://www.canchild.ca/en/ measures/gmfcs expanded revised.asp

71. Palisano R, Rosenbaum P, Walter S, et al. Development and reliability of a system to classify gross motor function in children with cerebral palsy. Dev Med Child Neurol 1997;39:214-23.

72. Palisano RJ, Rosenbaum P, Bartlett $\mathrm{D}$, et al. Content validity of the expanded and revised Gross Motor Function Classification System. Dev Med Child Neurol 2008;50:744-50.

73. Rosenbaum P, Paneth N, Leviton A, et al. A report: the definition and classification of cerebral palsy April 2006. Dev Med Child Neurol 2007;49:8-14.

74. Spittle AJ, Ferretti C, Anderson PJ, et al. Improving the outcome of infants born at $<30$ weeks' gestation-a randomized controlled trial of preventative care at home. BMC Pediatr 2009;9:73.

75. Brown NC, Doyle LW, Bear MJ, et al. Alterations in neurobehavior at term reflect differing perinatal exposures in very preterm infants. Pediatrics 2006;118:2461-71.

76. Natarajan G, Pappas A, Shankaran S, et al. Outcomes of extremely low birth weight infants with bronchopulmonary dysplasia: Impact of the physiologic definition. Early Hum Dev 2012;88:509-15.

77. Harwood RC, Kumar R, Travadi JN. Changing spectrum of necrotising enterocolitis. J Paediatr Child Health 2011;47:80.

78. Jobe AH, Bancalari E. Bronchopulmonary dysplasia. Am J Respir Crit Care Med 2001;163:1723-9.

79. Short EJ, Kirchner HL, Asaad GR, et al. Developmental sequelae in preterm infants having a diagnosis of bronchopulmonary dysplasia: Analysis using a severity-based classification system. Arch Pediatr Adolesc Med 2007:161:1082-7.

80. Department of Health $\mathrm{V}$, Australia. Bronchopulmonary dysplasia (BPD) in neonates. Secondary Bronchopulmonary dysplasia (BPD) in neonates 16.07.2014. 2014. http://www.health.vic.gov.au/ neonatalhandbook/conditions/bronchopulmonary-dysplasia.htm
81. Miltaha HR, Fahey LM, Sajous $\mathrm{CH}$, et al. Influence of perinatal factors in short- and long-term outcomes of infants born at 23 weeks of gestation. Am J Perinatol 2015;32:627.

82. Radic JAE, Vincer M, McNeely PD. Outcomes of intraventricular hemorrhage and posthemorrhagic hydrocephalus in a population-based cohort of very preterm infants born to residents of Nova Scotia from 1993 to 2010. J Neurosurg Pediatr 2015;15:580-8.

83. Network AaNZN. Australian and New Zealand Neonatal Network Data Dictionary 2015. 2015.

84. Cox JL, Holden JM, Sagovsky R. Detection of postnatal depression. Development of the 10-item Edinburgh Postnatal Depression Scale. Br J Psychiatry 1987;150:782-6.

85. Boyce P, Stubbs J, Todd A. The Edinburgh postnatal depression scale: validation for an Australian sample. Aust N Z J Psychiatry 1993;27:472-6.

86. Milgrom J, Ericksen J, Negri L, et al. Screening for postnatal depression in routine primary care: properties of the Edinburgh postnatal depression scale in an Australian sample. Aust $N Z J$ Psychiatry 2005;39:833-9.

87. Stein REK, Jessop DJ. The impact on family scale revisited: further psychometric data. J Dev Behav Pediatr 2003;24:9-16.

88. Williams AR, Piamjariyakul U, Williams PD, et al. Validity of the revised Impact on Family (IOF) scale. J Pediatr 2006;149:257-61.

89. APA. Impact on Family Scale, Construct: Parental perceptions of a child's medical condition on the family. Secondary Impact on Family Scale, Construct: Parental perceptions of a child's medical condition on the family. 2013. http://www.apa.org/pi/about/ publications/caregivers/practice-settings/assessment/tools/ family-impact.aspx

90. Woodward LJ, Mogridge N, Wells SW, et al. Can neurobehavioral examination predict the presence of cerebral injury in the very low birth weight infant? J Dev Behav Pediatr 2004;25:326-34

91. Einspieler C, Prechtl H, Bos A, et al. Prechtl's method on the qualitative assessment of general movements in preterm term and young infants. Cambridge University Press, Mac Keith Press, Clinics in Developmental Medicine, 2004.

92. Prechtl HFR, Einspieler C, Cioni G, et al. An early marker for neurological deficits after perinatal brain lesions. Lancet 1997:349:1361-3.

93. Sustersic B, Sustar K, Panjan DP. General movements of preterm infants in relation to their motor competence at five years. Eur $J$ Paediatr Neurol 2012;14:551-2.

94. Beccaria E, Martino M, Briatore E, et al. Poor repertoire General Movements predict some aspects of development outcome at 2 years in very preterm infants. Early Hum Dev 2012;88:393-6.

95. Kodric J, Sustersic B, Paro-Panjan D. Assessment of general movements and 2.5 year developmental outcomes: pilot results in a diverse preterm group. Eur J Paediatr Neurol 2010;14:131-7.

96. Lester BM, Andreozzi-Fontaine L, Tronick E, et al. Assessment and evaluation of the high risk neonate: the NICU Network Neurobehavioral Scale. J Vis Exp 2014;90:e3368.

97. Fink NS, Tronick E, Olson K, et al. Healthy newborns neurobehavior: norms and relations to medical and demographic factors. J Pediatr 2012;161:1073-9.e3.

98. Lester BM, Tronick EZ, LaGasse L, et al. Summary statistics of Neonatal Intensive Care Unit Network Neurobehavioral Scale scores from the maternal lifestyle study: a quasinormative sample. Pediatrics 2004;113(Suppl 2):668-75.

99. Tronick E, Lester BM. Grandchild of the NBAS: the NICU Network Neurobehavioral Scale (NNNS): a review of the research using the NNNS. J Child Adolesc Psychiatr Nurs 2013;26:193-203.

100. Piper MC, Darrah J. Motor assessment of the developing infant Alberta: Saunders, 1994.

101. Campbell SK, Kolobe THA, Wright BD, et al. Validity of the Test of Infant Motor Performance for prediction of 6-, 9- and 12-month scores on the Alberta Infant Motor Scale. Dev Med Child Neurol 2002;44:263-72.

102. van Haastert IC, De Vries LS, Helders PJ, et al. Early gross motor development of preterm infants according to the Alberta Infant Motor Scale. J Pediatr Psychol 2006;149:617-22.

103. Blanchard Y, Neilan E, Busanich J, et al. Interrater reliability of early intervention providers scoring the Alberta Infant Motor Scale. Pediatr Phys Ther 2004;16:13-18.

104. Jeng SF, Yau KI, Chen LC, et al. Alberta Infant Motor Scale: reliability and validity when used on preterm infants in Taiwan. Phys Ther 2000;80:168-78.

105. Bartlett DJ, Fanning JE. Use of the Alberta Infant Motor Scale to characterize the motor development of infants born preterm at eight months corrected age. Phys Occup Ther Pediatr 2003;23:31-45. 
106. Darrah J, Piper M, Watt MJ. Assessment of gross motor skills of at-risk infants: predictive validity of the Alberta Infant Motor Scale. Dev Med Child Neurol 1998;40:485-91.

107. Dunn $\mathbf{W}$. The impact of sensory processing abilities on the daily lives of young children and their families: a conceptual model. Infant Young Child 1997;9:23-35.

108. Dunn W. Infant/toddler sensory profile. User's manual. San Antonio: The Psychological Corporation, 2002.

109. Albers CA, Grieve AJ. Test Review: Bayley, N. (2006). Bayley scales of infant and toddler development, Vol 25. 3rd edn. San Antonio, TX: Harcourt Assessment. Journal of Psychoeducational Assessment, 2007:180-90.

110. Bode MM, D'Eugenio DB, Mettelman BB, et al. Predictive validity of the Bayley, third edition at 2 years for intelligence quotient at 4 years in preterm infants. J Dev Behav Pediatr 2014;35:570-5.

111. Msall ME. Measuring outcomes after extreme prematurity with the Bayley-III scales of infant and toddler development: a cautionary tale from Australia. Arch Pediatr Adolesc Med 2010;164:391-3.

112. Anderson PJ, De Luca CR, Hutchinson E, et al. Underestimation of developmental delay by the new Bayley-III scale. Arch Pediatr Adolesc Med 2010;164:352-6.

113. Johnson S, Moore T, Marlow N. Using the Bayley-III to assess neurodevelopmental delay: which cut-off should be used? Pediatr Res 2014;75:670-4.
114. Spencer-Smith MM, Spittle AJ, Lee KJ, et al. Bayley-III Cognitive and Language Scales in Preterm Children. Pediatrics 2015;135: e1258-65.

115. Harrison PL, Oakland T. Chapter 3-ABAS-II assessment methods. In: Thomas O, Patti LH, eds. Adaptive behavior assessment system-II. San Diego: Academic Press, 2008:37-9.

116. Harrison P, Oakland T. Adaptive Behaviour Assessment SystemThird Edition (ABAS-3): WPS, 2015.

117. Burns YR. Physiotherapy assessment for infants and young children. Brisbane: CopyRight Publishing Company Pty Ltd, 1992.

118. Burns YR, Ensbey RM, Norrie MA. The neuro-sensory motor developmental assessment part II: predictive and concurrent validity. Aust J Physiother 1989;35:151-7.

119. Carter AS, Briggs-Gowan M, Jones SM, et al. The Infant-Toddler Social and Emotional Assessment (ITSEA): factor structure, reliability, and validity. J Abnorm Child Psychol 2002;31: 495-514.

120. Liang K-Y, Zeger SL. Longitudinal data analysis using generalized linear models. Biometrika 1986;73:13-22.

121. Queensland. Department of Education. The Year 2 Diagnostic Net : information booklet for state schools. Brisbane, Qld: Publishing Services, Facilities and Services, Education Queensland, 1998. $48 p$. 